\title{
Dynamic Response of a Single Pile Embedded in Sand Including the Effect of Resonance
}

\author{
Mustafa Tolun, Buse Emirler², Abdulazim Yildiz², Hamza Güllü ${ }^{3}$ \\ ${ }^{1}$ Department of Civil Engineering, Adana Alparslan Turkes Science and Technology University, Çatalan Street, 01250 Sarıçam, \\ Adana, Turkey \\ 2 Department of Civil Engineering, Cukurova University, 01330 Sarıçam, Adana, Turkey \\ ${ }^{3}$ Department of Civil Engineering, Gaziantep University, University Boulevard, 27310 Şehitkamil, Gaziantep, Turkey \\ * Corresponding author, e-mail: mtolun@atu.edu.tr
}

Received: 27 September 2019, Accepted: 22 June 2020, Published online: 05 August 2020

\begin{abstract}
In this paper, responses of a single pile embedded in sand soil (loose and dense) under dynamic loading (sinusoidal dynamic vibrations of $0.1 \mathrm{~g}$ to $0.5 \mathrm{~g}$ ) have been investigated by two-dimensional analysis using the finite element method (FEM). Viscous (dashpot) boundaries have been used for taking the boundary effects of far-field into account. The applicability and accuracy of site responses of two-dimensional analysis due to the FEM modelling have been well verified with one-dimensional site responses. The results indicate that the relative density of sand (loose, dense) becomes prominent for the displacements of the pile, specifically under the frequency effects of resonance. While the pile in loose sand causes the displacements of $0.1 \mathrm{~m}$ to $0.5 \mathrm{~m}$, the pile in dense sand leads to the displacements of $0.05 \mathrm{~m}$ to $0.25 \mathrm{~m}$, proportionally with the dynamic loads from $0.1 \mathrm{~g}$ to $0.5 \mathrm{~g}$. Moreover, the displacements reach their peak value at the frequency ratio of the resonance case. Viscous boundaries are found sufficient for modelling excessive displacements due to dynamic loading. However, the displacements reveal that high vibrations (> $0.1 \mathrm{~g}$ for loose sand, > $0.2 \mathrm{~g}$ for dense sand) influencing the pile deformations are critical for the issues of settlements. This is more significant for the resonance case in order for ensuring sufficient design. Consequently, the findings from the study are promising good contributions for pile design under the dynamic effect.
\end{abstract}

\section{Keywords}

single pile, sand, dynamic effect, sinusoidal vibration, resonance, displacement

\section{Introduction}

The investigation of pile responses, which has a significant role in the geotechnical applications of poor soils, due to dynamic loading (earthquake loads, wind loads, wave loads, vibratory machine loads etc.) becomes a significant concern for the engineers in practice [1]. Although the numerical efforts about the pile responses under static loading are relatively wide, the studies about dynamic loading are less due to its complicated nature of modelling. Thus, they still need further research. The theoretical, experimental, and numerical studies on the behavior of a single pile under the dynamic load can be observed in earlier works [2-6]. The horizontal movement of the end pile embedded in a homogeneous soil is studied against earthquake response as one of the first studies [3]. On the other hand, both the horizontal and vertical movements of the end pile embedded in a homogeneous soil are investigated in a further study [7]. These earlier studies have provided a fundamental idea for understanding the behavior of the pile-soil system [6]. The earlier efforts are extended by some researchers [8-14] by conducting experimental works on the behavior of piles under the dynamic load. Moreover, the studies are experimentally improved by conducting centrifuge tests [15-18].

Even though the experiments of pile under dynamic loading are limited, their results still provide good insights for the experimenters in practice. Shake table tests (using $60 \%$ relative density of sand soil and a rigid steel plate (14.1 tons) placed on the top of the piles to represent the superstructure) are carried out to evaluate the effect of the piles damaged by strong ground motion on the superstructure [19]. It is observed that that maximum bending occurred in the piles is about $1.5 \mathrm{~m}$ below the superstructure 
and at the top of the piles. It is also noted that dynamic load lead to large displacements at the ground surface resulting in the superstructure to move $36 \mathrm{~cm}$ horizontally. Largescale shake table and centrifuge experiments (representing the superstructure by a mass of 15.6 tons placed at the top of the pile group in the layout $2 \times 2$ ) are conducted to study the behavior of piles under dynamic loading [20]. It is found that maximum deformations are developed at the top of the piles. The results from two experiments are observed well compatible. Centrifuge tests are carried out for investigation of the effects of different dynamic amplitudes (by sinusoidal dynamic loads of $0.08 \mathrm{~g}$ and $0.47 \mathrm{~g}$ ) on a single pile embedded in saturated sand [21]. The bending moments due to high vibration $(0.47 \mathrm{~g})$ are obtained larger than the ones due to low vibration $(0.08 \mathrm{~g})$. The amplitude of vibration is found significant on the pile response. Shake table tests are performed to study the rigid piles embedded in silty clay soil conditions under different dynamic loadings [22]. A granular material (sand and gravel) is placed between pile and foundation for using as a cushion. From the testing, the bending moments are found zero at the top of pile due to the granular material. It is stated that the granular material is able to decrease the bending moments at the top of pile. The lateral capacity, ductility and energy dissipation capacity of single piles (number of 18 aluminium model piles) with different cross-section (square, circular and hexagon) embedded in the sand (with two relative densities of $30 \%$ and $70 \%$ ) are experimentally investigated under the dynamic load [23]. The lateral capacity and the energy dissipation capacity of piles in the dense sand are obtained higher than the ones of loose sand. This is attributed to the increase of shear resistance due to stiffness of the dense sand. At a constant level of displacement, the piles with circular cross-sections become most favorite regarding the energy dissipation capacity for both loose and dense sand. A series of shake table tests are conducted to study the behavior of axially loaded of $3 \times 1$ pile group with or without a raft foundation [14]. Total displacements (vertical) of the pile group with the raft foundation are measured 2 times smaller than the ones of the pile group without the raft foundation. It can be proposed that construction raft foundation over the pile group is able to reduce the displacements.

Numerical modelling of experimental efforts is relatively beneficial for further criticism of dynamic loadings. The finite element method (FEM) is known as one of the favorite methods frequently used for modelling the behavior of piles under the dynamic load in a linear elastic and homogeneous soil in previous efforts [6, 24-28]. It is observed that FEM mostly gives accurate results matching with experiments that validate numerical modelling. A comparison of the centrifuge test and numerical model (using PILE-3D-EFF code based on the finite element method) is performed for the responses of a single pile in the sand under the dynamic load [29]. The bending moments using the FEM is well matching with the ones of testing under the vibrations that represent the weak and strong ground motions in both. Three-dimensional numerical analyses (using the code of DIANA-J3) are performed to investigate the laterally loaded piles embedded in the sand [30]. The numerical results (maximum horizontal displacement occurring on the pile head) are estimated well consistent with the results from the shake table test until approximately the fourth-second of the testing and then continue with less consistency. A numerical model (using finite element method via the code of DGPILE-3D) of pile group embedded in the sand (loose and dense) under dynamic loading is compared with centrifuge tests [31]. The accelerations and bending moments in the piles estimated from numerical analysis (i.e. finite element method) are in a good agreement with the ones measured from centrifuge tests. Using the finite element method, two-dimensional analysis (using the code of PLAXIS 2D) has been performed for respond of the soil located below an embankment with or without mini piles under the dynamic load [32]. It is estimated that maximum accelerations at the midpoint of the embankment with the case of mini-piles are smaller than the ones from without mini-piles.

Despite the significant efforts in earlier studies, it is observed that numerically investigations of a single pile embedded in the sand under the dynamic load (sinusoidal motion) are still insufficient regarding the effects of dynamic amplitudes and frequencies. Moreover, this is the most concerned with the responses specifically under resonance effects. In this paper, displacements of a single pile embedded in the sand (loose and dense sand) have been numerically investigated under dynamic loading (sinusoidal motion) regarding the acceleration and frequency effects. In view of this, the effect of resonance frequency between sand and dynamic loading is considered as a particular attempt for the pile displacement. Twodimensional analysis has been performed using the finite element method for pile responses. It is believed that the findings obtained from the study could be beneficial for the engineers in practice for the settlement issues of pile design against the dynamic load. 


\section{Materials and methodology}

Numerical investigations throughout the study for the responses of the single pile embedded in the sand (with the relative densities of loose and dense states) under dynamic influences are performed in two-dimensional (2D) analysis using PLAXIS 2D [33]. Under the employed conditions presented below, the effects of the relative density of sand, amplitude (acceleration) of the dynamic load (vibration of sinusoidal motion) and frequency on the respond of the pile have been computed in the numerical analyses. The resonance influence is figured out by a particular concern in the computations.

\subsection{Description of materials}

An advanced site characteristic (i.e. including hardening soil model) studied in this article are presented in Table 1 for loose sand (relative density of $30 \%$ ) and dense sand (relative density of $80 \%$ ). Since using accurate soil model is essential for the prediction of soil responses, the numerical analyses in this article have been carried out employing the hardening soil model to reflect the behavior of sand more realistically [34]. The suitable employment of the model parameters of soil such as the unit weight, second stiffness, tangent stiffness, angle of internal friction, angle of dilatancy and cohesion, etc., has been benefited from past work by using their proposed formulas [35].

$$
\begin{aligned}
& \gamma_{d r y}=15+4.0(R D / 100)\left[k N / \mathrm{m}^{3}\right] \\
& \gamma_{\text {sat }}=19+1.6(R D / 100)\left[\mathrm{kN} / \mathrm{m}^{3}\right]
\end{aligned}
$$

Readers interested in the technical details of the model parameter can apply to the past studies mentioned above.

As for the pile properties, a cylindrical concrete pile presented in Table 2 including material characteristics is used throughout the study. As shown in the table, the pile is mechanically behaved as a linear elastic material with the damping ratios of $5 \%$ generally proposed in concrete applications [36-39]. A deep foundation can be defined as a pile foundation if the ratio of the pile depth to the pile diameter is greater than 4 [40]. Thus, while the pile diameter of $0.4 \mathrm{~m}$ is selected, the ratio of pile depth to pile diameter is equal to 10 , that value is employed for dynamic analysis. The diameter of $0.4 \mathrm{~m}$ could be adequately considered for numerical investigation, due to some limitations (i.e. time consumption, computational effort, etc.) in computational methods. Moreover, the pile model is studied with axial symmetry, owing to its circular shape on the plan, during the numerical analysis under the dynamic load.
Table 1 The properties of sand regarding for hardening soil mode

\begin{tabular}{lcc}
\hline Parameters & Loose & Dense \\
\hline Dry unit weight of sand, $\gamma_{\mathrm{dry}}\left(\mathrm{kN} / \mathrm{m}^{3}\right)$ & 16.2 & 18.2 \\
Secand stiffness, $E_{50}\left(\mathrm{kN} / \mathrm{m}^{2}\right)$ & 18000 & 48000 \\
Tangent stiffness, $E_{\text {eod }}\left(\mathrm{kN} / \mathrm{m}^{2}\right)$ & 18000 & 48000 \\
Unloading/Reloading stiffness, $E_{\mathrm{ur}}\left(\mathrm{kN} / \mathrm{m}^{2}\right)$ & 54000 & 144000 \\
Angle of internal friction, $\phi\left(^{\circ}\right)$ & 32 & 38 \\
Angle of dilatancy, $\psi\left({ }^{\circ}\right)$ & 2 & 8 \\
Cohesion, $c\left(\mathrm{kN} / \mathrm{m}^{2}\right)$ & 0.1 & 0.1 \\
Damping ratio, $\xi(\%)$ & 5.0 & 5.0 \\
Poisson's ratio, $v$ & 0.2 & 0.2 \\
Power for stress-level dependency of stiffness, $m$ & 0.60 & 0.45 \\
Failure ratio, $R_{f}$ & 0.9625 & 0.9000 \\
\hline
\end{tabular}

Table 2 The material properties of the pile

\begin{tabular}{lc}
\hline Parameters & Properties \\
\hline Material model & Linear elastic \\
Unit weight of concrete, $\gamma\left(\mathrm{kN} / \mathrm{m}^{3}\right)$ & 24.0 \\
Young's modulus, $E\left(\mathrm{kN} / \mathrm{m}^{2}\right)$ & $3 \times 107$ \\
Poisson's ratio, $v$ & 0.2 \\
Damping ratio, $\xi(\%)$ & 5.0 \\
\hline
\end{tabular}

\subsection{Methodology: modelling of pile-soil system}

For modelling the near field of pile and substructure (soil) in the article, finite element method (FEM) is used for the numerical investigations. The FEM can be described by the responses of nodal points combined by discrete elements in soil body [41]. It relatively becomes a powerful tool for engineering applications with a limited size of boundary dimensions, while large dimensions of soil body lead to some restrictions [42].

The basic equation for the time-dependent movement of a volume under the influence a (dynamic) load is given below.

$M . \ddot{u}+C . \dot{u}+K . u=P(t)$

Here, $M$ is the mass matrix, $C$ is the damping matrix, $K$ is the stiffness matrix, $u$ is the displacement vector and $\mathrm{P}$ is the load vector. The displacement $(u)$, the velocity $(\dot{u})$ and the acceleration $(\ddot{u})$ can vary with time. The last two terms in the foregoing equation $(K . u=P)$ correspond to the static deformation. In the matrix $M$, the mass of the materials (soil + water + any constructions) is considered and that matrix is implemented as a lumped matrix. Since numerical analyses are performed in dry sand conditions (soil + any constructions), therefore the liquefaction is not considered in the study. The matrix $C$ represents the material damping of the materials. Material damping is caused 
by friction or by irreversible deformations (plasticity or viscosity). In order to define the damping matrix, extra parameters are required, which are difficult to determine from experiments. In addition to this, Rayleigh damping, which is partially compatible with experimental data, can be used for the classical damping model. In this damping model, $C$ is formulated as a function of the mass and stiffness matrices as given below.

$$
C=\alpha_{0} \cdot M+\alpha_{1} \cdot K
$$

Here, when the contribution of $M$ is dominant, more of the low-frequency vibrations are damped, and when the contribution $f K$ is dominant, more of the high-frequency vibrations are damped as shown in Fig. 1 [43].

The modelling of the far-field (around the soil body) is built with a relatively reliable artificial boundary called viscous boundary or dashpot boundary (where the stress waves hitting the model boundaries are damped without reflecting back due to damping). The viscous boundary provides satisfactory responses for body waves because they absorb reflected energy by the advantage of using frequency independence to applied stresses [42].

It is known that the boundary dimensions of substructure model under dynamic excitations are generally larger than static analysis otherwise stress waves will be reflected leading to distortions in the computed results [44]. However, locating the boundaries far away requires many extra elements and therefore a lot of extra memory and calculating time. Thus, it is necessary to define an optimum dimension for modelling. This is because modelling by smaller dimensions does not reflect dynamic deformations well, while large ones need a huge amount of effort in calculation time and computational memory. Hence, the finite element modelling of the near field in this study is constructed within the vertical and horizontal lengths of $8 \mathrm{~m}$ and $80 \mathrm{~m}$, respectively. It is demonstrated from the trials of horizontal lengths $(50 \mathrm{~m}, 60 \mathrm{~m}, 70 \mathrm{~m}, 80 \mathrm{~m}, 90 \mathrm{~m}$ and $100 \mathrm{~m}$ ) that there is no significant effect on the deformations under dynamic load beyond the distance of $80 \mathrm{~m}$. On the other hand, the vertical length is restricted to $8 \mathrm{~m}$, because the surface layers nearly within $30 \mathrm{~m}$ depth are more prominently amplified under dynamic load $[45,46]$.

Using the finite element methods in most numerical methods, the geometry is divided up into several elements forming a mesh or grid. It is also known that the element size affects the outputs such as stress, strain and displacement. Thus, in order for providing more precise outputs, the element size should be chosen small sizes as far as can be

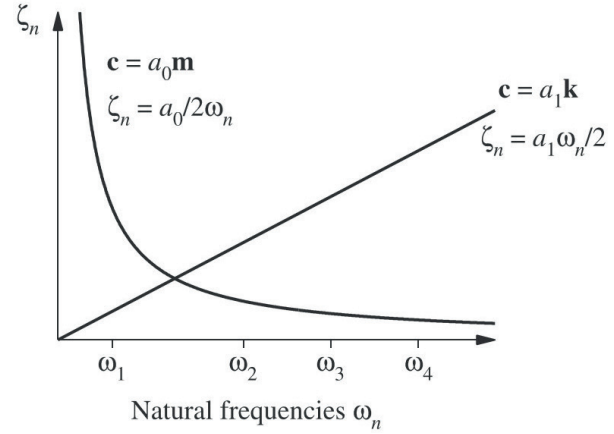

(a)

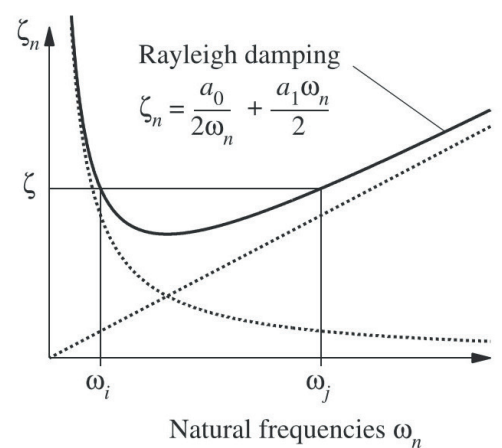

(b)

Fig. 1 Variation of modal damping ratios with natural frequency: (a) Mass-proportional damping and stiffness-proportional damping,

(b) Rayleigh damping [43]

done. In this article, five different mesh densities from very coarse to very fine sizes are tested. Then, the meshes of the finite elements have been chosen as very fine size for all analyses to avoid the effect of the mesh density. Moreover, the described pile-soil modelling is illustrated in Fig. 2.

For a robust numerically investigation of dynamic excitation on the pile embedded in both loose soil (sand) and dense soil (sand), a verification of soil natural frequency (with different relative densities) in the proposed model between the free vibration analysis numerically and the corresponding formulas analytically can be strongly recommended before an extensive dynamic effort. This would provide the dynamic responses of the pile-soil system to be accurately ensured during estimations. It is essential that the fundamental frequency for both soil and structure becomes crucial for understanding the resonance case under dynamic excitation [47]. For the homogeneous soil deposit with a constant shear wave velocity resting on rigid bedrock proposed in the study, the fundamental frequency can be analytically determined by successive formulas (i.e. $T_{n}=4 H /\left(V_{s}(2 n-1)\right), V_{s}=(G / \rho)^{0.5}, \rho=\gamma / g$, $G=E / 2(1+v)), f_{n}=1 / T_{n}$, where, $V_{s}, H, T_{n}, G, \rho, E, v, \gamma, g$, $f_{n}$, are equal to shear wave velocity, layer thickness, natural period corresponding to $n^{\text {th }}$ mode of vibration, shear 


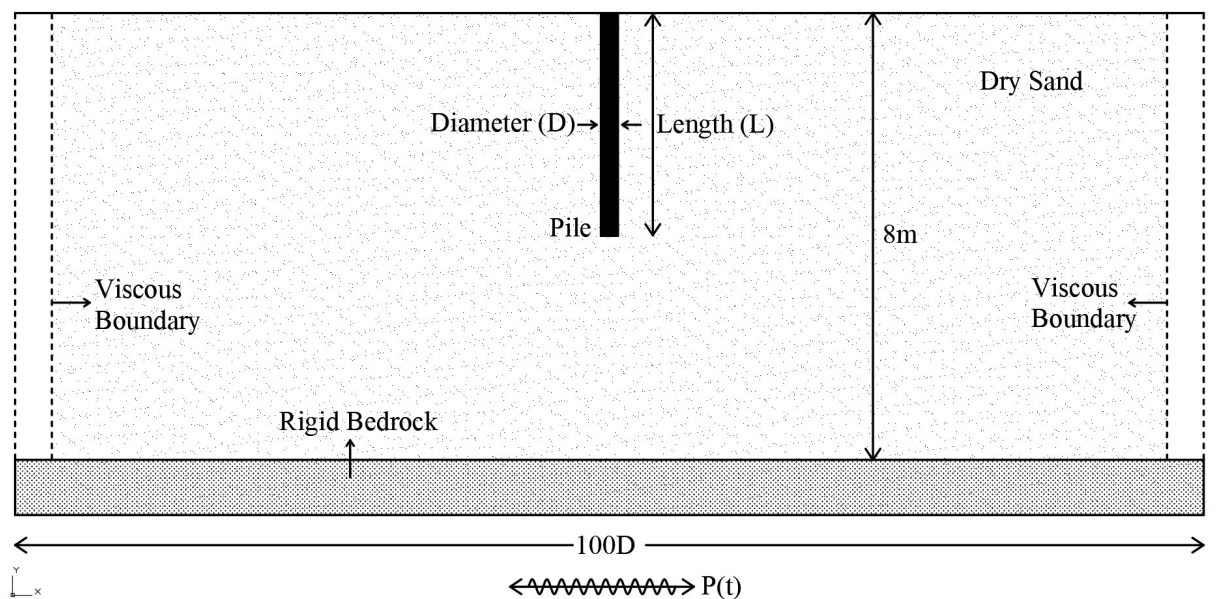

(a) Pile-soil system and boundary conditions

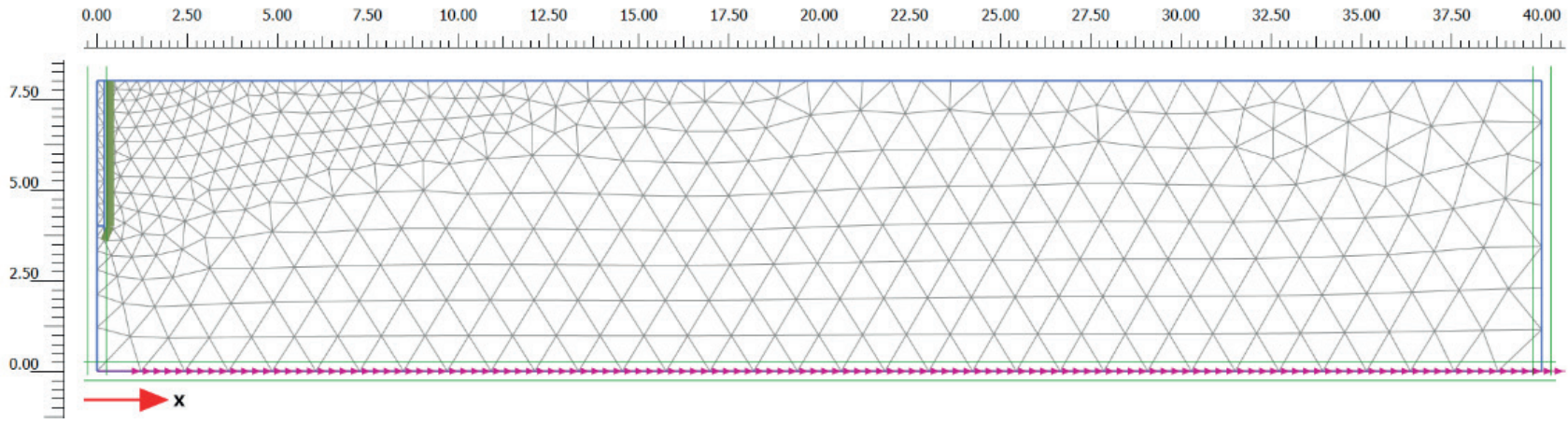

(b) The finite element mesh used in numerical analyses

Fig. 2 Description of the pile-soil model system

modulus, density, Young's modulus, Poisson's ratio, unit weight, gravity acceleration and natural frequency, respectively) $[47,48]$. The comparisons of frequency estimations numerically (free vibration) and analytically versus relative density of sand are shown in Fig. 3. For the same relative density, it can be seen from the frequencies that the numerical estimations (free vibration) are not much different from the analytical results. Thus, for the proposed model (Fig. 2), it can be concluded that the numerical analysis can be realistically considered for further dynamic investigations. When compared the estimations of the natural frequency of soils in past works, it is observed that while some researchers use the numerical approach (free vibration analysis) [49], others prefer analytical approach dependent upon experiments [50]. In this present study, the loose sand and the dense sand respectively having the relative density of $30 \%$ and $80 \%$ are studied for investigation the pile responses under dynamic effects. Their natural frequencies are estimated as $2.80 \mathrm{~Hz}$ (for loose sand) and $4.50 \mathrm{~Hz}$ (for dense sand) which are obtained from the free vibration analyses where the finite element model has only soil body and no structural elements.

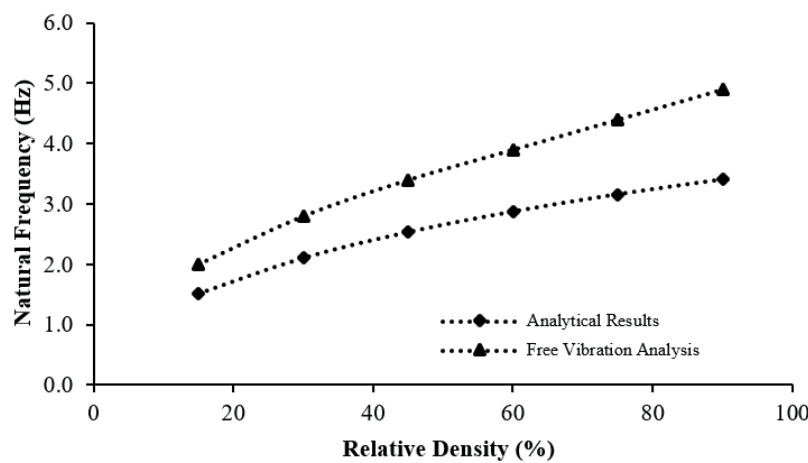

Fig. 3 The natural frequency values of soil for different relative densities

\subsection{Comparison of site response effect for $1 D$ and 2D analyses}

Prior to the 2D numerical effort of the employed model throughout the study, it could be valuable to compare its site response performances with one-dimensional analysis. This comparison could be considered as a validation of the $2 \mathrm{D}$ numerical analysis. As it is known that the soil and bedrock surfaces are infinitely extended in a horizontal direction by the assumption of shear wave ( $\mathrm{SH}$ ) in the vertical direction. It can be noted that the ground responses 
obtained from the presumptive methods (1D, 2D) are reasonably compatible with the responses measured during many earthquakes [47]. In this article, the performances of 2D dynamic site effects (i.e. from PLAXIS 2D) has been compared with the one-dimensional site effects obtained from the code of DEEPSOIL [51]. It is reported that DEEPSOIL relatively enables to perform one-dimensional seismic site response analysis by equivalent linear and nonlinear behaviors widely used in most of the practical applications [52]. This ability of DEEPSOIL allows researchers to conduct unprecedently large-scale simulations by capturing the effects of variability and uncertainty of soil, and dynamic motions.

For comparison, a sinusoidal motion (vibration) with the maximum amplitude of $0.1 \mathrm{~g}$ and a frequency of $3 \mathrm{~Hz}$ has been applied to the loose sand from the base (bedrock) for 5 seconds. The surface responses of the sinusoidal motion by the site responses of the $1 \mathrm{D}$ and $2 \mathrm{D}$ analysis are illustrated in Fig. 4. From the plots, while the maximum amplitude of $0.79 \mathrm{~g}$ is resulted by $1 \mathrm{D}$ analysis, 2D analysis yields to the maximum amplitude of $0.80 \mathrm{~g}$. It can be said that that the one-dimensional analysis responses similar amplitudes to the ones of two-dimensional analysis. Thus, 2D-site effects can be considered as verified with 1D-site effects. Because of the responses, it is understood that the $2 \mathrm{D}$ numerical analysis employed in this article could potentially offer the site effects accurately and reliably.

One and two-dimensional ground response analysis by modelling a high sand column which is assumed to have a constant shear modulus through the depth of the profile is carried out by Ertugrul [53]. Obtained results are similar for the two different analysis methods. In order to compare one and two-dimensional ground response analysis, some studies are performed by Pehlivan et al. [54]. The results show that multiple one-dimensional analysis can generate median response spectra across at 100-m wide region of interest that are similar to two-dimensional analysis.

\section{Result and discussion}

\subsection{Effect of relative density of sand under resonance case}

Using 2D numerical analysis, the effect of the relative density of sand $\left(D_{r}=30 \%\right.$ for loose sand, $D_{r}=80 \%$ for dense sand) has been investigated regarding the resonance influences between dynamic load and sand (without pile). A frequency of dynamic load that is similar to the frequency of sand is applied for the satisfaction of resonance condition. The response and behavior of machine foundations resting on dry sand are investigated by Al-Mosawi et al. [55].
The experimental results show that the maximum sand displacement occurs at the resonance frequency. For the estimations, while the maximum amplitude of $0.1 \mathrm{~g}$ is used for the sinusoidal dynamic motion, the frequencies of dynamic motion are employed as $2.80 \mathrm{~Hz}$ and $4.50 \mathrm{~Hz}$ that respectively represent frequencies of loose and dense sands under dynamic load. The resonance results (at a specific point of $\mathrm{x}$-direction of $40.0 \mathrm{~m}$, y-direction of $8.0 \mathrm{~m}$ at the soil surface) of dynamic motion for loose and dense sands are illustrated in Figs. 5-6 respectively for the amplitudes of acceleration and displacement.

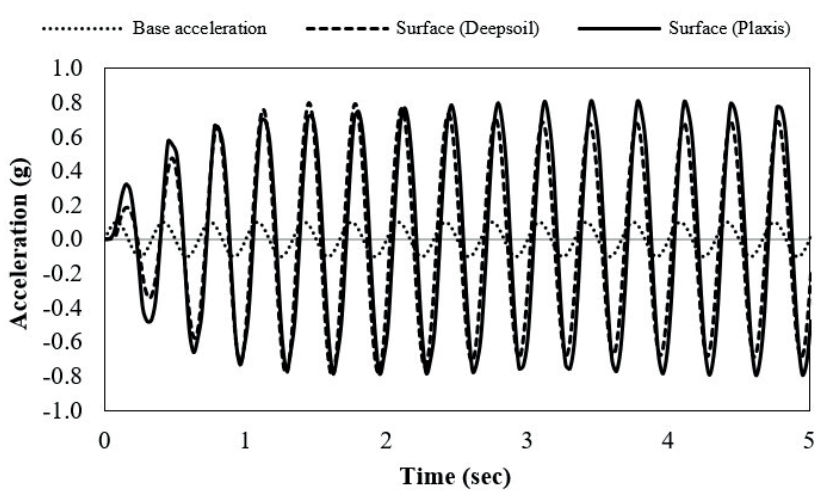

Fig. 4 Comparison of dynamic motions due to the 1D and 2D site response analysis

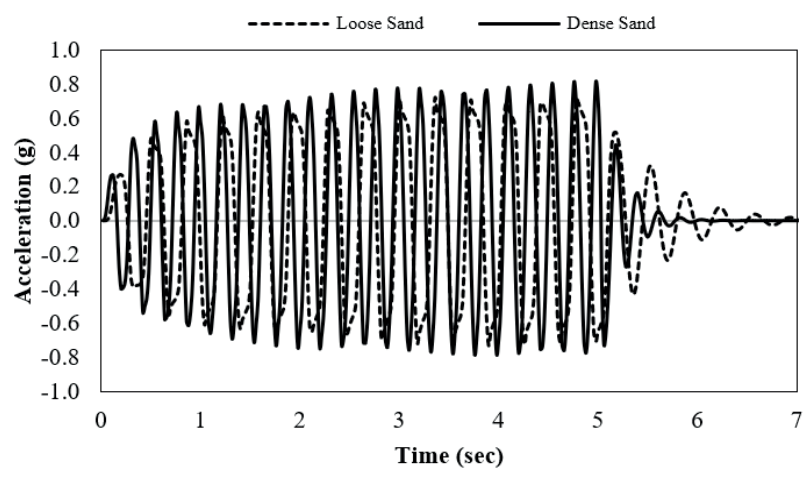

Fig. 5 Resonance influence of sinusoidal motion regarding the acceleration values for the loose and dense sand at the soil surface

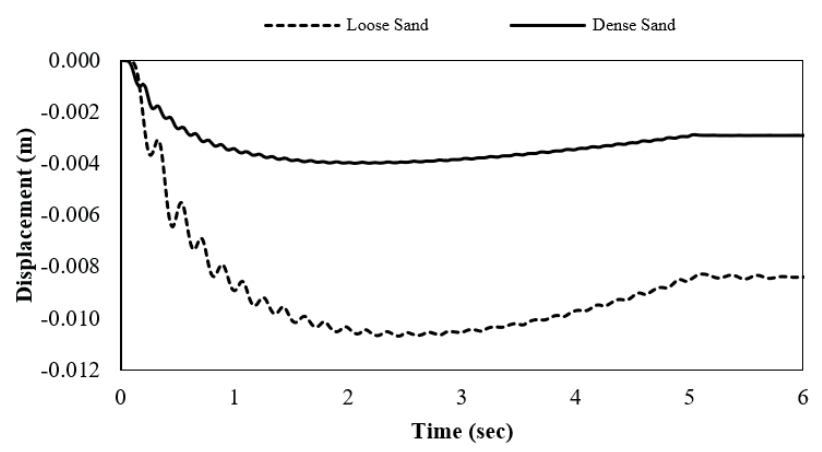

Fig. 6 Resonance influence of sinusoidal motion regarding the displacement values for the loose and dense sand at the soil surface 
Under resonance effect of the dynamic motion of $0.1 \mathrm{~g}$, the loose sand is able to amplify up to $0.73 \mathrm{~g}$, while the dense sand is able to reach to $0.82 \mathrm{~g}$ (Fig. 5). Even though similar maximum amplitudes are obtained under accelerations of sinusoidal motion, the sinusoidal motions through the loose and dense sands are different due to their different frequencies. As expected, it is observed that loose sand is amplified later than the dense sand due to its higher natural period (or lower natural frequency). The findings (Fig. 6) can be observed well comparable with the past effort that performs centrifuge tests [31]. Similarly, the loose sand $\left(D_{r}=27 \%\right)$ is found to produce significant accelerations that reach to ones of dense sand $\left(D_{r}=73 \%\right)$. As for the displacement amplitudes (Fig. 6), maximum displacements are estimated to be $0.011 \mathrm{~m}$ and $0.004 \mathrm{~m}$ for the loose and dense conditions, respectively. While the loose sand leads to large displacements, the dense sand results in small displacements. This is clear evidence that the relative density of sand plays a significant role in the displacements under dynamic motion. Moreover, it can be concluded that the loose sand results in the responses of significantly higher displacements than the ones of dense sand under resonance frequency of dynamic vibration. Hence, it can be said that dynamic motion under resonance effect becomes relatively prominent on the deformations specifically for poor soils (loose sand in this study).

\subsection{Effect of dynamic load under resonance case}

Understanding the pile responses against the dynamic motion is prominent for the issues of dynamic design in sand soils $[6,14,17]$. Thus, the responses (acceleration, vertical displacement) of pile founded in loose and dense sands are investigated in this section under various accelerations of dynamic load (i.e. sinusoidal vibration). For dynamic responses, the vibrations of sinusoidal motions of $0.1 \mathrm{~g}$,
$0.2 \mathrm{~g}, 0.3 \mathrm{~g}, 0.4 \mathrm{~g}$ and $0.5 \mathrm{~g}$ are applied to the sand from base (bedrock) for 2 seconds. In order to obtain the maximum response of pile, the vibration time of 2 seconds is found sufficient after many trials, thus no further time performance is attempted. For properly modelling the frictional interactions between the concrete pile and sand, the interface elements are adequately defined regarding the relative density of sand (loose, dense). The dynamic responses (acceleration, displacement) of the pile are estimated at the head of the pile. Moreover, distributions of displacements are displayed for an arbitrary vibration of $0.3 \mathrm{~g}$ for understanding the modifications and boundary effects within the near field of pile and substructure (sand).

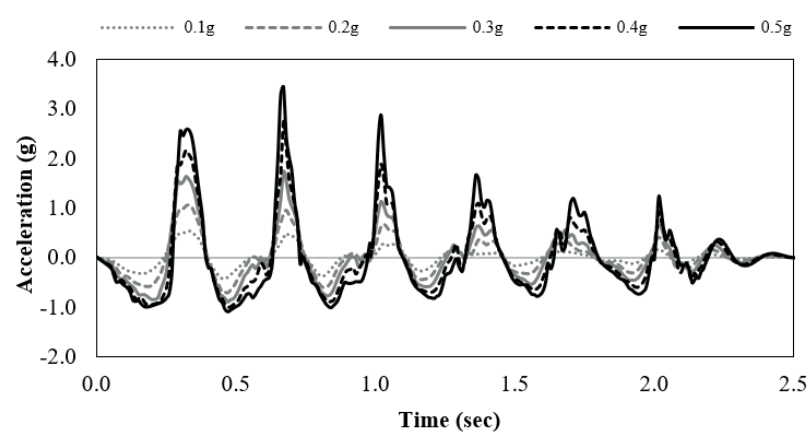

Fig. 7 The accelerations at the pile head in the loose sand for different amplitudes

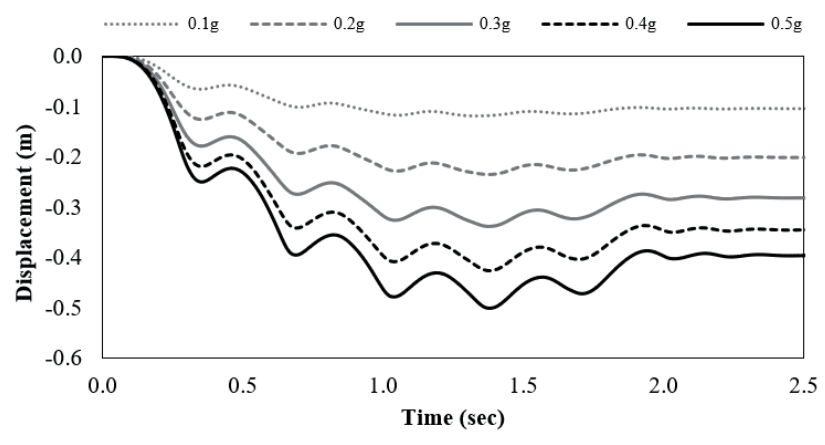

Fig. 8 The displacements at the pile head in the loose sand for different amplitudes

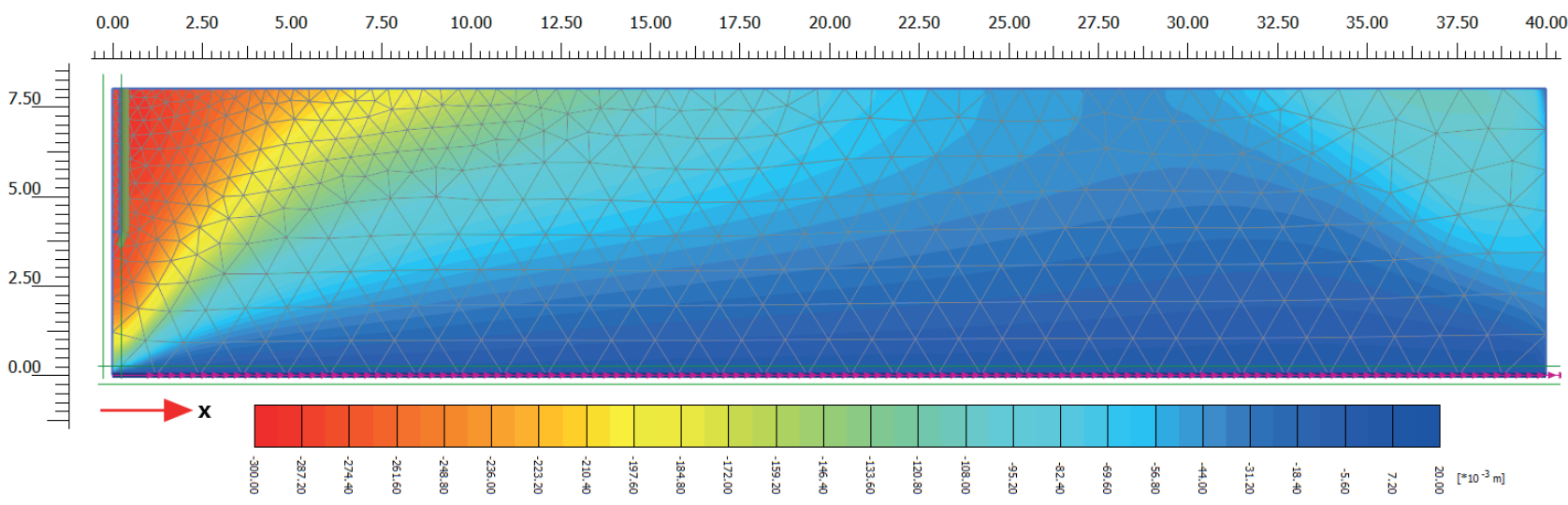

Fig. 9 The displacement distribution occurring around the pile in the loose sand 
The results of dynamic effects are illustrated in the plots of Figs. 7-9 for loose sand and in Figs. 10-12 for dense sand. It is found that the accelerations and displacements at pile head increase with the increased dynamic load for both loose and dense sand. Moreover, loose sands result in higher responses of amplitudes than dense sands. This clearly indicates that relative density is prominent for the pile-founded sand under vibration. Under the base vibrations of $0.1 \mathrm{~g}$ to $0.5 \mathrm{~g}$, the pile in loose sand is able to response the accelerations of $0.5 \mathrm{~g}$ to $3.5 \mathrm{~g}$ (Fig. 7), while the pile in dense sand can lead to amplify the accelerations of $0.5 \mathrm{~g}$ to $2.5 \mathrm{~g}$ (Fig. 10). Similarly, the pile in loose sands results in the displacements of $0.10 \mathrm{~m}$ to $0.50 \mathrm{~m}$ (Fig. 8), while the pile in dense sand leads to the displacements of $0.05 \mathrm{~m}$ to $0.25 \mathrm{~m}$ (Fig. 11).

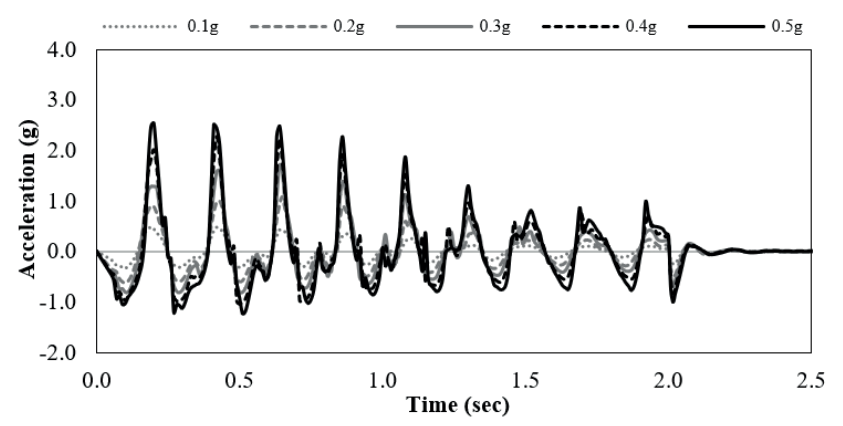

Fig. 10 The accelerations at the pile head in the dense sand for different amplitudes

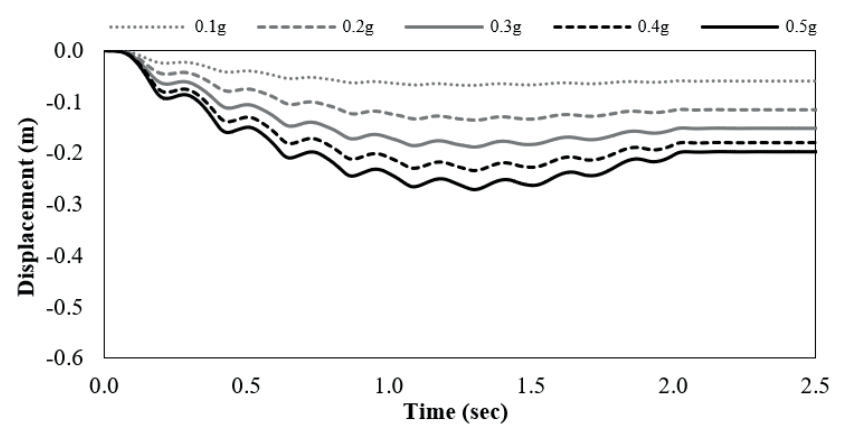

Fig. 11 The displacements at the pile head in the dense sand for different amplitudes
For the design issues, settlements due to the pile displacements obtained by the vibrations greater than $0.1 \mathrm{~g}$ can be considered high for the loose sand, recommended in past work (Table 3) [56].

A similar concern is valid for the dense sand under the vibrations greater than $0.2 \mathrm{~g}$. Hence, dynamic effects should not be underestimated during the design of pile specifically for loose sands. Regarding the distribution of displacements under dynamic loadings (Figs. 9 and 12), it is seen that the pile is severely modified around the surrounding area.

It is clear from the distributions of displacement that the near-field substructure is more influenced due to the pile in loose sand compared to dense sand. While the displacements in loose sand appear to minimize beyond the distance at least by two times of pile depth, the ones in dense sand are minimized beyond the distance by one time of pile depth. The modifications indicate that boundary conditions (i.e. boundary lengths and model (dashpot) is adequate in this article. The dimensions of dissipation (minimization) of dynamic effects around the pile here can be well comparable with reflexive waves studied in past works. It is reported that the effects of reflexive waves are negligible within 3-4 times of the foundation radius in the horizontal direction and 2-3 times of the foundation radius in the vertical direction $[57,58]$.

\subsection{Effect of various frequencies of dynamic load}

The frequency of dynamic load for the pile embedded in the sand under a dynamic load can significantly influence the resulting responses (displacement) of the pile-soil system. A numerical study is performed by Ertugrul [53] in order

Table 3 Typical allowable total settlements for foundation design [56]

\begin{tabular}{lc}
\hline Type of structure & Typical allowable total settlement (mm) \\
\hline Office buildings & $12-50$ \\
Heavy industrial buildings & $25-75$ \\
Bridges & 50 \\
\hline
\end{tabular}

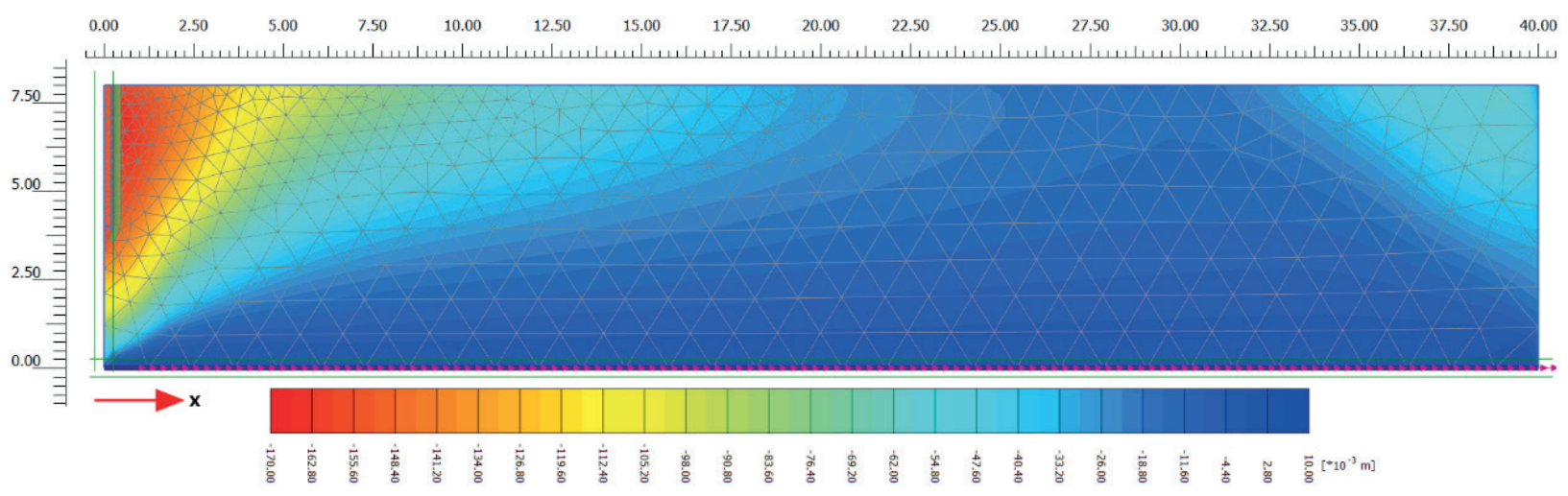

Fig. 12 The displacement distribution occurring around the pile in the dense sand 
to understand the effects of input base excitation characteristics (peak acceleration amplitude and frequency of the excitation), soil strength on the dynamic response of cantilever earth-retaining walls. Analyses show that the base motion frequency becomes an important factor on magnitudes of dynamic thrust when it approaches the natural frequency of the system.

So as to investigate the effect of frequency, there are two ways to follow; (using a dynamic load with various frequencies while keeping the constant the natural frequency of soil, or else using a dynamic load with constant frequency while changing the natural frequency of soil). Since the latter is more difficult than the former, it is chosen the first way in this section. Hence, different ratios of the various frequencies of a dynamic load (with $0.1 \mathrm{~g}$ amplitude) to a constant frequency (natural frequency) of sands $\left(w_{n}=2.80 \mathrm{~Hz}\right.$ for loose and $w_{n}=4.50 \mathrm{~Hz}$ for dense) shown in Table 4 are numerically analysed and estimated for understanding the effect of frequency on the vertical displacement of pile. Here, it can be noted that the frequency ratio $\left(w / w_{n}\right)$ of 1 means resonance case, where the
Table 4 Frequencies of the dynamic load for different $\left(w / w_{n}\right)$ ratios

\begin{tabular}{lccc}
\hline Amplitude $(\mathrm{g})$ & $w / w_{n}$ & $w$ for loose $(\mathrm{Hz})$ & $w$ for dense $(\mathrm{Hz})$ \\
\hline 0.1 & 0.75 & 2.100 & 3.375 \\
0.1 & 1.00 & & \\
& $($ resonance) & 2.800 & 4.500 \\
0.1 & 1.25 & 3.500 & 5.625 \\
0.1 & 1.50 & 4.200 & 6.750 \\
0.1 & 1.75 & 4.900 & 7.875 \\
\hline \multirow{2}{*}{$w=$ frequency of dynamic load; $w$} & $=$ natural frequency of sand
\end{tabular}

$w=$ frequency of dynamic load; $w_{n}=$ natural frequency of sand

frequency of vibration equals to the natural frequency of sand. These ratio values were selected because the dynamic magnification factor generally reaches its maximum values while the frequency ratio is between 0.5 and 2.0 [43].

The resulting displacements at the pile head versus frequency ratios are illustrated in Fig. 13 for loose sand and in Fig. 14 for dense sand. It is found that displacements are in an uptrend with increased frequency ratios up to the resonance case $\left(w / w_{n}=1\right)$. They reach to a peak value at the resonance that indicates the priority of frequency effect under resonance condition. Beyond the resonance, they decrease with frequency ratios. The displacement of the
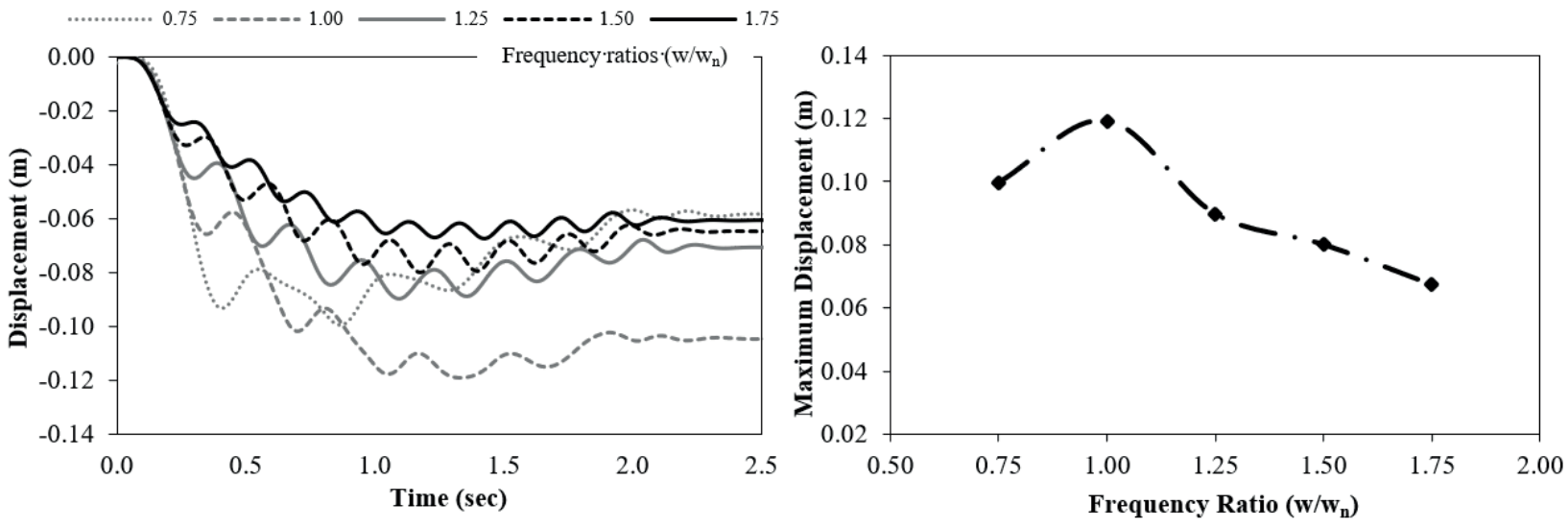

Fig. 13 The displacements at the pile head in the loose sand for different frequency ratios
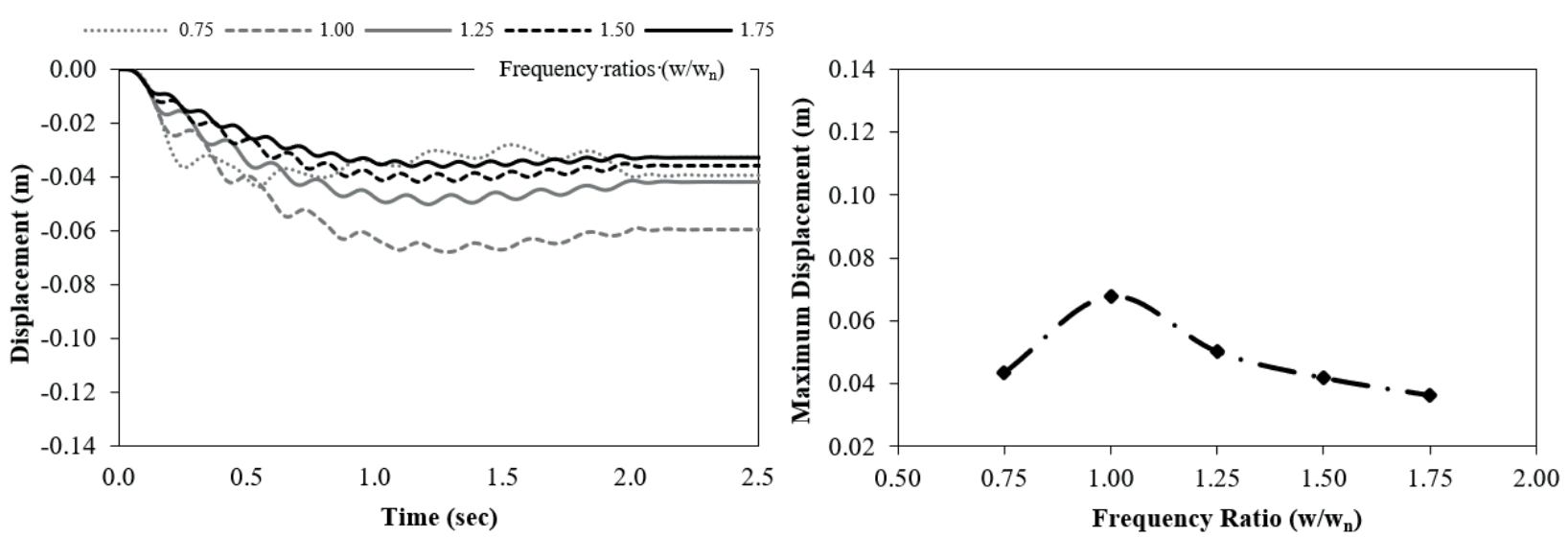

Fig. 14 The displacements at the pile head in the dense sand for different frequency ratios 
pile in loose sand yields to $0.12 \mathrm{~m}$ under the resonance frequency $\left(w / w_{n}=1\right)$, while the dense sand results in $0.07 \mathrm{~m}$. It is important to remember the fact that the strong ground motion is mostly amplified dependent upon its frequency content as well as the soil characteristic [59, 60, 61].

From the results, it is clear that pile embedded in loose sand is amplified the displacement larger than the one which is embedded in dense sand. This indicates that loose soils are more prone to frequency effects resulting in high deformations under vibration. Concerning with the dynamic behavior of soil, it is well established that the characteristic (i.e. stiffness) of super and sub substructures largely depends on the frequency content of the dynamic load [60,61].

It can be noted that all the displacements due to the frequency effects (except for the loose sand at the resonance condition) under the vibration of $0.1 \mathrm{~g}$ here are acceptable (Table 3) for the design issues of settlement by pile foundation. However, the settlements due to the displacements larger than the vibration of $0.1 \mathrm{~g}$ as emphasized earlier should rigorously be assessed for the frequency effects during the pile design. Alternately, the pile dimensions employed in this study should be revised against adverse vibrations (i.e. $>0.1 \mathrm{~g}$ ) in order for ensuring sufficient design. This is specifically prominent for resonance case.

The time-frequency computational method is proposed by Changwei et al. [62] based on the elastic wave theory and Hilbert-Huang transform, which is full three-dimensional nonlinear time history analysis method in order to investigate seismic active earth pressure of rigid retaining wall. The results show that the frequency of seismic wave has a significant effect on the resultant force of seismic active earth pressure and the critical rupture angle of backfill soil.

\section{Conclusions}

Responses of a single pile embedded loose and dense sands have numerically investigated under the dynamic load in this study. In summary, two-dimensional analysis has been performed using the finite element method. Absorbent (viscous or dashpot) boundaries have been used for accounting the boundary effects of far-field (i.e. around soil body). Prior to further analysis, soil response of two-dimensional analysis here has been well confirmed with one-dimensional site response analysis. Under the employed conditions in the study, the effects of the relative density of sand, amplitude (acceleration) of dynamic load (vibration of sinusoidal motion) and frequency have been estimated for the responses of the pile, specifically for displacements. Resonance effect has also been evaluated by great concern. It has been observed that the results obtained in the study are presenting good insights specifically for the design issues of pile settlements. However, as a final remark, they require a testing confirmation (shake table) as a separate topic in a future study. On the basis of the numerical effort given in the study, the following main concluding remarks can be proposed for the pile embedded loose and dense sands under the dynamic effect:

Regarding the soil (loose and dense sand) without pile under the dynamic load of resonance frequencies (acceleration of $0.1 \mathrm{~g}$, and resonance frequencies of $2.80 \mathrm{~Hz}$ for loose sand, $4.50 \mathrm{~Hz}$ for dense sand), the relative density is found prominent on the displacements at the soil surface. It is obtained that the loose sand is amplified later than the dense sand due to its higher natural period (or lower natural frequency), as expected. Consequently, the loose sand is found to response significantly higher displacements than the ones of dense sand under resonance frequency of dynamic vibration.

On the effect of dynamic load ( $0.1 \mathrm{~g}$ to $0.5 \mathrm{~g})$ to the pilesoil system, the accelerations and displacements at pile head are found to increase with the increased dynamic load for both loose and dense sand. Again, loose sand results in higher responses than dense sand. While the pile in loose sands results in the displacements of $0.1 \mathrm{~m}$ to $0.5 \mathrm{~m}$, the pile in dense sand leads to the displacements of $0.05 \mathrm{~m}$ to $0.25 \mathrm{~m}$. Thus, it can be concluded that displacements of the pile due to high vibrations $(>0.1 \mathrm{~g}$ for loose sand, $>0.2 \mathrm{~g}$ for dense sand) should be assessed as out of acceptable levels for the issues of settlements during pile design.

On the effect of the surrounding area of the pile due to an arbitrary dynamic load $(0.3 \mathrm{~g})$, the pile is severely modified around the surrounding area. The near-field substructure is more influenced due to the pile in loose sand compared to dense sand. While the displacements can be neglected beyond the distance at least two times of pile depth for loose sand, the ones in dense sand can be neglected beyond the distance at one time of pile depth. The modifications indicate that boundary conditions (i.e. boundary lengths and model (dashpot) are adequately designed for the pile-soil system.

On the effect of frequency, it is found that the influences (displacements) on the pile increase with frequency ratio up to the resonance case and reach their peak value at the resonance. Beyond that resonance, they decrease with the increase of the frequency ratios. Again, it is found that the resonance effect becomes prominent on the magnitude of 
displacements. The displacement of the pile in loose sand yields to $0.12 \mathrm{~m}$ under the resonance frequency $\left(w / w_{n}=1\right)$, while the dense sand results in $0.07 \mathrm{~m}$ that are all acceptable for settlement issues. However, higher vibrations of

\section{References}

[1] Siyahi, B., Cetin, K. Ö., Bilge, T. "Geoteknik deprem mühendisliği açısından zemin-temel-yapı etkileşimine kritik bakış" (Critical view of ground-foundation-structure interaction in terms of geotechnical earthquake engineering), Türkiye Mühendislik Haberleri, 484, pp. 41-50, 2015. (in Turkish)

[2] Parmelee, R. A., Penzien, J., Scheffey, C. F., Seed, H. B., Thiers, G. R. "Seismic effects on structures supported on piles extending through deep sensitive clay", Institute of Engineering Research, University of California, Berkeley, CA, USA, Rep. 64-2, 1964.

[3] Tajimi, H. "Earthquake response of foundation structures", Faculty of Science and Engineering, Nihon University, Tokyo, Japan, 1966. (in Japanese)

[4] Penzien, J. "Soil-pile foundation interaction", In: Wiegel, R. L. (ed.) Earthquake Engineering, Prentice-Hall, Englewood Cliffs, NJ, USA, 1970, pp. 349-381.

[5] Novak, M. "Dynamic Stiffness and Damping of Piles", Canadian Geotechnical Journal, 11(4), pp. 574-598, 1974. https://doi.org/10.1139/t74-059

[6] Novak, M. "Piles Under Dynamic Loads", In: Proceedings of the 2nd International Conference on Recent Advances in Geotechnical Earthquake Engineering and Soil Dynamics, St. Louis, MO, USA, 1991, pp. 2433-2456. [online] Available at: https://scholarsmine. mst.edu/icrageesd/02icrageesd/session14/12

[7] Nogami, T., Novak, M. "Soil-pile interaction in vertical vibration", Earthquake Engineering \& Structural Dynamics, 4(3), pp. 277-293, 1976.

https://doi.org/10.1002/eqe.4290040308

[8] Mizuno, H., Iiba, M., Kitagawa, Y. "Shaking table testing of seismic building-pile-soil interaction", In: Proceedings of the 8th World Conference Earthquake Engineering, San Francisco, CA, USA, 1984, pp. 649-656. [online] Available at: https://www.iitk.ac.in/ nicee/wcee/article/8_vol3_649.pdf

[9] Han, Y., Novak, M. "Dynamic behaviour of single piles under strong harmonic excitation", Canadian Geotechnical Journal, 25(3), pp. 523-534, 1988. https://doi.org/10.1139/t88-057

[10] Nomura, S., Shamoto, Y., Tokimatsu, K. "Soil-pile-structure interaction during liquefaction", In: Proceedings of the 2nd International Conference on Recent Advances in Geotechnical Earthquake Engineering and Soil Dynamics, St. Louis, MO, USA, 1991, pp. 743-750. [online] Available at: https://scholarsmine.mst.edu/ icrageesd/02icrageesd/session05/40

[11] Murono, T., Nishumura, A., Nagazuma, M. "Model test on a grouppile considering the vibration of ground in seismic evaluation", In: Proceedings of the 24th JSCE Earthquake Engineering Symposium, Tokyo, Japan, 1997, pp. 625-628. (in Japanese)

[12] Tokimatsu, K., Suzuki, H. "Pore Water Pressure Response Around Pile and its Effects on P-Y behavior During Soil Liquefaction", Soils and Foundations, 44(6), pp. 101-110, 2004.

https://doi.org/10.3208/sandf.44.6 101 dynamic load $(>0.1 \mathrm{~g})$ could result in high displacements that require a revision of pile dimensions against the adverse effects of frequency variations during the pile design. This is specifically prominent for the resonance case.

[13] Ishizaki, S., Tokimatsu, K., Nagao, T. "Overview of semi-rigid pile head connection methods and their effect on buildings in liquefiable soil", In: Proceedings of the 9th International Conference on Testing and Design Methods for Deep Foundations, Kanazawa, Japan, 2012, pp. 13-24.

[14] Unsever, Y. S., Matsumoto, T., Esashi, K., Kobayashi, S. "Behaviour of model pile foundations under dynamic loads in saturated sand", Bulletin of Earthquake Engineering, 15, pp. 1355-1373, 2017. https://doi.org/10.1007/s10518-016-0029-y

[15] Cheney, J. A., Brown, R. K., Dhat, N. R., Hor, O. Y. Z. "Modelling Free-Field Conditions in Centrifuge Models", Journal of Geotechnical Engineering, 116(9), pp. 1347-1367, 1990. https://doi.org/10.1061/(ASCE)0733-9410(1990)116:9(1347)

[16] Horikoshi, K., Matsumoto, T., Hashizume, Y., Watanabe, T., Fukuyama, H. "Performance of piled raft foundations subjected to static horizontal loads", International Journal of Physical Modelling in Geotechnics, 3(2), pp. 37-50, 2003. https://doi.org/10.1680/ijpmg.2003.030204

[17] Horikoshi, K., Matsumoto, T., Hashizume, Y., Watanabe, T. "Performance of piled raft foundations subjected to dynamic loading", International Journal of Physical Modelling in Geotechnics, 3(2), pp. 51-62, 2003. https://doi.org/10.1680/ijpmg.2003.030205

[18] Matsumoto, T. "Implications for Design of Piled Raft Foundations Subjected Lateral Loading", In: Proceedings of the International Symposium on Advances in Foundation Engineering, Singapore, 2013, pp. 113-136.

[19] Tamura, S., Suzuki, Y., Tsuchiya, T., Fujii, S., Kagawa, T. "Dynamic response and failure mechanisms of a pile foundation during soil liquefaction by shaking table test with a large-scale laminar shear box", presented at 12th World Conference on Earthquake Engineering, Auckland, New Zealand, Jan. 30 - Feb. 4, 2000.

[20] Kagawa, T., Sato, M., Minowa, C., Abe, A., Tazoh, T. "Centrifuge Simulations of Large-Scale Shaking Table Tests: Case Studies", Journal of Geotechnical and Geoenvironmental Engineering, 130(7), pp. 663-672, 2004. https://doi.org/10.1061/(ASCE)1090-0241(2004)130:7(663)

[21] Su, D., Li, X. S. "Effect of shaking intensity on seismic response of single-pile foundation in liquefiable soil", In: Proceedings of the GeoShanghai International Conference, Shanghai, China, 2006, pp. 379-386.

https://doi.org/10.1061/40864(196)51

[22] Song, E., Wu, S. "Seismic Analysis of Rigid Pile Composite Ground", In: US-China Workshop on Ground Improvement Technologies, Orlando, FL, USA, 2009, pp. 189-197. https://doi.org/10.1061/41025(338)20

[23] Raongjant, W., Jing, M. "Experimental investigation on seismic behavior of single piles in sandy soil", Earthquake Engineering and Engineering Vibration, 10, pp. 417-422, 2011. https://doi.org/10.1007/s11803-011-0077-x 
[24] Blaney, G. W., Kausel, E., Roesset, J. M. "Dynamic stiffness of piles", In: 2nd International Conference on Numerical Methods in Geomechanics, Blacksburg, VI, USA, 1976, pp. 1001-1012.

[25] Wolf, J. P., von Arx, G. A. "Impedance functions of a group of vertical piles", In: Proceedings of the 10th Conference on Earthquake Engineering and Soil Dynamics, Pasadena, CA, USA, 1978, pp. 1-22.

[26] Kuhlemeyer, R. L. "Static and Dynamic Laterally Loaded Floating Piles", Journal of the Geotechnical Engineering Division, 105(2), pp. 289-304, 1979.

[27] Waas, G., Hartmann, H. G. "Pile foundations subjected to dynamic horizontal loads", presented at European Simulation Meeting, Modelling and Simulation of Large-Scale Structural Systems, Capri, Italy, Sept. 24-25, 1981.

[28] Sanchez-Salinero, I., Roesset, J. "Static and dynamic stiffnesses of single piles", University of Texas, Austin, TX, USA, Rep. GR82-31, 1982.

[29] Finn, W. D. L., Fujita, N. "Piles in liquefiable soils: seismic analysis and design issues", Soil Dynamics and Earthquake Engineering, 22(9-12), pp. 731-742, 2002. https://doi.org/10.1016/S0267-7261(02)00094-5

[30] Cubrinovski, M., Sugita, H., Tokimatsu, K., Sato, M., Ishihara, K., Tsukamoto, Y., Kamata, T. "3-D numerical simulation of shake-table tests on piles subjected to lateral spreading", University of Canterbury, In: TC4 Geotechnical Earthquake Engineering Satellite Conference, Osaka, Japan, 2005, pp. 199-206. [online] Available at: http://hdl.handle.net/10092/2180

[31] Zhang, F., Okawa, K., Kimura, M. "Centrifuge model test on dynamic behavior of group-pile foundation with inclined piles and its numerical simulation", Frontiers of Architecture and Civil Engineering, 2(3), pp. 233-241, 2008 https://oi.org/10.1007/s11709-008-0033-7

[32] Wang, Z., Mei, G., Cai, G., Yu, X. "Dynamic Finite Element Analysis of Micropile Foundation in Subgrade", presented at GeoHunan International Conference, Hunan, China, Aug. 3-6, 2009. https://doi.org/10.1061/41044(351)22

[33] Bentley "PLAXIS 2D Geotechnical Finite Element Software" [computer program] Available at: https://www.bentley.com/en/ products/product-line/geotechnical-engineering-software/plaxis-2d

[34] Schanz, T., Vermeer, P. A., Bonnier, P. G. "The hardening soil model: formulation and verification", In: Beyond 2000 in Computational Geotechnics, Amsterdam, The Netherlands, 1999, pp. 281-296. [online] Available at: https://www.plaxis.com/content/uploads/ import $/ \mathrm{kb} / \mathrm{kb}$-publications/The $\% 20$ Hardening $\% 20$ Soi $1 \% 20$ Model\%20-\%20Formulation\%20and\%20Verfication.pdf

[35] Brinkgreve, R. B. J., Engin, E., Engin, H. K. "Validation of empirical formulas to derive model parameters for sands", In: 7th European Conference on Numerical Methods in Geotechnical Engineering, Trondheim, Norway, 2010, pp. 137-142.

[36] Choudhury, D. "Soil dynamics", Indian Institute of Technology, Bombay, India, Lecture notes, 2012.

[37] Mazzotta, V., Brunesi, E., Nascimbene, R. "Numerical Modeling and Seismic Analysis of Tall Steel Buildings with Braced Frame Systems", Periodica Polytechnica Civil Engineering, 61(2), pp. 196-208, 2017.

https://doi.org/10.3311/PPci.9469
[38] Benahmed, B., Hammoutene, M., Cardone, D. "Effects of Damping Uncertainties on Damping Reduction Factors", Periodica Polytechnica Civil Engineering, 61(2), pp. 341-350, 2017. https://doi.org/10.3311/PPci.9665

[39] Benahmed, B., Hamoutenne, M. "Use of the Artificial Neural Networks to Estimate the DRF for Eurocode 8", Periodica Polytechnica Civil Engineering, 62(2), pp. 470-479, 2018. https://doi.org/10.3311/PPci.8139

[40] Das, B. M. "Principles of foundation engineering", Cengage Learning, Stamford, CT, USA, 2011.

[41] Zienkiewicz, O., Taylor, R., Zhu, J. Z. "The finite element method: its basis and fundamentals", Elsevier, Oxford, UK, 2005.

[42] Cakir, T. "Evaluation of the effect of earthquake frequency content on seismic behaviour of cantilever retaining wall including soilstructure interaction", Soil Dynamics and Earthquake Engineering, 45, pp. 96-111, 2013. https://doi.org/10.1016/j.soildyn.2012.11.008

[43] Chopra, A. K. "Dynamics of Structures: Theory and Applications to Earthquake Engineering", Pearson, London, UK, 2013. https://doi.org/10.1007/BF00426980

[44] Ordu, E., Özkan, M. T. "Three-dimensional finite element analysis of the seismic behaviour of pile foundations", Itüdergisi/d mühendislik, 5(2), pp. 27-34, 2006. (in Turkish) [online] Available at: http:// itudergi.itu.edu.tr/index.php/itudergisi_d/article/view/536

[45] Power, M. S., Chang, C. Y., Idriss, I. M. "Variation of earthquake ground motion with depth", In: 3rd US National Conference on Earthquake Engineering, Charleston, USA, 1986, pp. 369-380.

[46] Ansal, A. M., Lav, A. M., Iyisan, R., Erken A. "Effect of geotechnical factors in March 13, 1992 Erzincan earthquake, performance of ground and soil structure during earthquakes", In: 13th International Conference on Soil Mechanics and Foundation Engineering, New Delhi, India, 1994, pp. 49-54.

[47] Kramer, S. L. "Geotechnical earthquake engineering", Prentice Hall, Upper Saddle River, NJ, USA, 1996.

[48] Kanai, K. "The requisite conditions for the predominant vibration of ground", Bulletin of the Earthquake Research Institute, 35, pp. 457-471, 1957.

[49] Oliaei, M., Tohidifar, H. "Seismic stability of slopes reinforced with sleeved and unsleeved piles", European Journal of Environmental and Civil Engineering, 24(8), pp. 1091-1119, 2018. https://doi.org/10.1080/19648189.2018.1447515

[50] Ge, Q., Xiong, F., Zhang, J., Chen, J. "Shaking table test of dynamic interaction of soil-high-rise buildings", European Journal of Environmental and Civil Engineering, 21(3), pp. 249-271, 2017. https://doi.org/10.1080/19648189.2015.1110057

[51] Hashash, Y. M. A., Musgrove, M. I., Harmon, J. A., Groholski, D. R., Phillips, C. A., Park, D. "DEEPSOIL 6.0 User Manual", University of Illinois, Urbana-Champaign, IL, USA, 2015.

[52] Musgrove, M., Harmon, J., Hashash, Y. M. A., Rathje, E. "Evaluation of the DEEPSOIL Software on the DesignSafe Cyberinfrastructure", Journal of Geotechnical and Geoenvironmental Engineering, 143(9), Article number: 02817005-1, 2017. https://doi.org/10.1061/(ASCE)GT.1943-5606.0001755 
[53] Ertugrul, L. O. "A finite element modelling study on the seismic response of cantilever retaining walls", MSc Thesis, Middle East Technical University, 2006

[54] Pehlivan, M., Rathje, E. M., Gilbert, R. B. "Influence of 1D and 2D spatial variability on site response analysis", presented at 15 th World Conference on Earthquake Engineering, Lisbon, Portugal, Sept. 24-28, 2012.

[55] Al-Mosawi, M. J., Fattah, M. Y., Al-Ameri, A. F. I. "Effect of saturation of sandy soil on the displacement amplitude of soil foundation system under vibration", Journal of Engineering, 21(2), pp. 20-36, 2015. [online] Available at: http://joe.uobaghdad.edu.iq/ index.php/main/article/view/463

[56] Coduto, D. P. "Foundation Design: Principles and Practices", Prentice-Hall, NJ, USA, 2001.

[57] Tabatabaiefar, H. R., Massumi, A. "A simplified method to determine seismic responses of reinforced concrete moment resisting building frames under influence of soil-structure interaction", Soil Dynamics and Earthquake Engineering, 30(11), pp. 1259-1267, 2010. https://doi.org/10.1016/j.soildyn.2010.05.008
[58] Ghandil, M., Behnamfar, F. "Ductility demands of MRF structures on soft soils considering soil-structure interaction", Soil Dynamics and Earthquake Engineering, 92, pp. 203-214, 2017.

https://doi.org/10.1016/j.soildyn.2016.09.051

[59] Wolf, J. P. "Dynamic soil-structure interaction", Prentice-Hall, NJ, USA, 1985.

[60] Vlassis, A. G., Spyrakos, C. C. "Seismically isolated bridge piers on shallow soil stratum with soil-structure interaction", Computers and Structures, 79(32), pp. 2847-2861, 2001. https://doi.org/10.1016/S0045-7949(01)00105-5

[61] Güllü, H., Jaf, H. S. "Full 3D nonlinear time history analysis of dynamic soil-structure interaction for a historical masonry arch bridge", Environmental Earth Sciences, 75, Article number: 1421, 2016. https://oi.org/10.1007/s12665-016-6230-0

[62] Changwei, Y., Jianjing, Z., Zhengzheng, W., Licong, C. "Research on time-frequency analysis method of active earth pressure of rigid retaining wall subjected to earthquake", Environmental Earth Sciences, 77, Article number: 232, 2018. https://doi.org/10.1007/s12665-018-7325-6 